\title{
Podocyte-Associated Molecules in Puromycin Aminonucleoside Nephrosis of the Rat
}

\author{
Pauliina Luimula, Niclas Sandström, Dmitry Novikov, and Harry Holthöfer \\ Haartman Institute, Department of Bacteriology and Immunology, University of Helsinki, and University of Helsinki \\ Central Hospital, Helsinki, Finland
}

\begin{abstract}
SUMMARY: Molecules of central functional significance for the glomerular podocytes are rapidly emerging and have been shown to be distinctly involved in diseases with altered glomerular filtration barrier. Here we used the puromycin aminonucleoside (PA) nephrosis model in the rat to study some key proteins associated with the maintenance of the functional glomerular filtration barrier in vivo. The molecules studied included the filtration slit component nephrin, the hairpin-like membrane protein podocin, the basolateral adhesion molecules $\beta 1$ integrin and $\alpha$-dystroglycan, and the cytoskeleton-linking intermediary $\beta$-catenin and the actin-associated $\alpha$-actinin-4. The results showed diminished protein levels of podocin and nephrin in the PA-treated group. $\beta$-catenin showed distinct down-regulation at 3 days of induction, and the control level was reached at 10 days. $\beta 1$ integrin was markedly up-regulated during induction. $\alpha$-actinin- 4 was not changed at the studied time points. The results show distinct differences in the different domains of podocytes during PA-induced proteinuria. (Lab Invest 2002, 82:713-718).
\end{abstract}

$R$ etraction of podocyte foot processes leading to flattening is found as a shared morphologic feature in severe proteinuric states (Kanwar et al, 1991; Kerjaschki, 1994). Simultaneously, the interpodocyte slit diaphragms are either totally lost or possibly internalized and replaced by direct contacts of the adjacent simplified foot processes. To study the molecular mechanisms involved in the impairment of the glomerular ultrafiltration barrier manifesting as proteinuria, the well-established puromycin aminonucleoside nephrosis (PAN) rat model closely resembling human minimal change nephropathy (Caulfield et al, 1976) was chosen.

In this model, the characteristic morphologic and functional changes most likely involve the various proteins that link the protein complex at the slit diaphragm to the cytoskeleton. This is based on observations of the rearrangement of the cytoskeleton seen in proteinuria (Kubosawa and Kondo, 1994; Whiteside et al, 1993). We and others have previously shown that nephrin, a key component of the slit diaphragm, is distinctly regulated in the PAN model (Kawachi et al, 2000; Luimula et al, 2000).

The changes in the expression levels of other proteins associated with the slit diaphragm domain are not known as to the PAN model. Because the slit

\section{DOI: 10.1097/01.LAB.0000017168.26718.16}

Received November 27, 2001.

Pauliina Luimula and Niclas Sandström contributed equally to this study. This work was supported by grants from the Finnish Cultural Foundation, the Maud Kuistila Foundation, the Sigrid Juselius Foundation, the University of Helsinki, the Päivikki and Sakari Sohlberg Foundation, and the European Union (grant QLRT-1999-30619).

Address reprint requests to: Dr. Harry Holthöfer, Haartman Institutel Department of Bacteriology and Immunology, Biomedicum Helsinki, Molecular Medicine, University of Helsinki, PB 63 (Haartmaninkatu 8), FIN-00014 Helsinki, Finland.E-mail: Harry.Holthofer@Helsinki.Fi proposedly is a modified adherens junction (Reiser et al, 2000), it was of interest to include also an analysis of changes in cadherin, typical of these junctional complexes, in the glomeruli of PAN rats. On the other hand, the basal aspect of podocytes is attached, in a firm but dynamic way, to the underlying glomerular basement membrane (GBM) by integrins (Kreidberg, 2000), and supposedly by dystroglycan, and therefore these molecules were included as well.

To study the complex mechanism of PAN, we measured the expression levels of nephrin, podocin, P-cadherin, $\beta 1$ integrin, $\alpha$-dystroglycan, and $\beta$-catenin, as well as that of $\alpha$-actinin- 4 , a recently discovered proteinuria-associated molecule of the cytoskeleton (Kaplan et al, 2000). These molecules were analyzed at mRNA or at both mRNA and protein levels.

\section{Results}

\section{Urinary Albumin}

According to the previously described PAN model in the rat (Caulfield et al, 1976), the single intraperitoneal injection of PA led to a gradual increase of proteinuria, starting at Day 3 and peaking at Day 10 after injection. The urinary albumin levels are presented in Figure 1.

\section{Effects on mRNA}

To determine the effects of puromycin aminonucleoside (PA) treatment on the mRNA expression of the chosen molecules, we performed semiquantitative RT-PCR and compared the mRNA levels between the PA-treated group and the controls. Podocin and $\alpha$-actinin-4-specific mRNA levels showed 1.6- and 2-fold up-regulation, respectively, at 3 days of puromycintreatment and remained at an elevated level at 10 days (1.6- and 1.63-fold, respectively). The expression lev- 


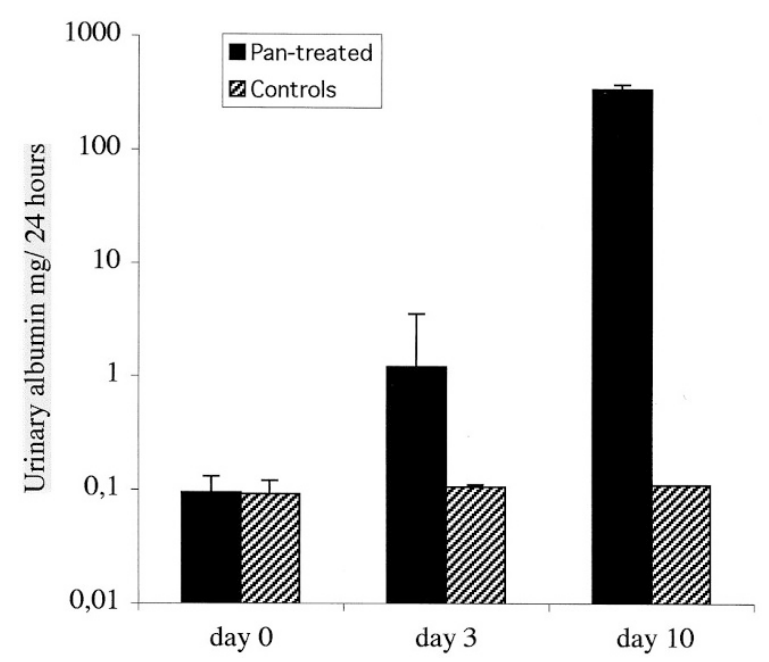

Figure 1.

Daily albuminuria in the puromycin-treated rats detected by nephelometry. Pan $=$ puromycin aminonucleoside nephrosis.

els of $\alpha$-dystroglycan-, $\beta 1$-integrin-, and P-cadherinspecific mRNAs did not show any significant changes at any time point (Fig. 2). We have previously shown a remarkable down-regulation of nephrin at the same time points (Luimula et al, 2000).

\section{Effects on Proteins}

To quantitate the particular proteins in a proteinuric disease induced by PA, we measured protein levels by quantitative Western blotting. The most apparent change was a 2 -fold rise in $\beta 1$ integrin protein at both days 3 and 10. Additionally, the level of podocin showed a nearly $50 \%$ decrease at 3 days and was still remarkably decreased at 10 days of puromycin treatment, being $10 \%$ of control at Day 10 . The pattern of reduction was similar to that of nephrin (Fig. 4). No appreciable alterations were

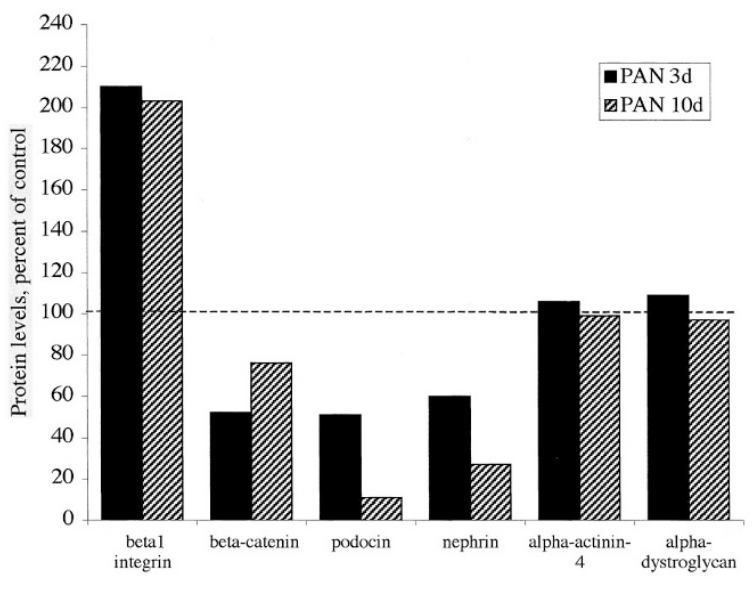

Figure 3.

A schematic presentation of protein levels. The total protein concentrations of the lysates were measured by BCA protein assay, and an equalized amount of each sample was run on an $8 \%$ SDS-PAGE. Each run was performed in triplicate. Bars show the measured mean values. The dotted line represents the control level.

seen in the expression level of either $\alpha$-actinin-4 (Figs. 3 and 4 ) or $\alpha$-dystroglycan. The $\beta$-catenin level decreased by more than $50 \%$ at 3 days, but levels similar to control were gained back at 10 days (Fig. 3).

\section{Immunofluorescence}

In immunofluorescence microscopy, closely comparable changes in the staining intensities with mono- ( $\beta 1$ integrin) and polyclonal (podocin) antibodies were found between control kidneys and kidneys of PA-

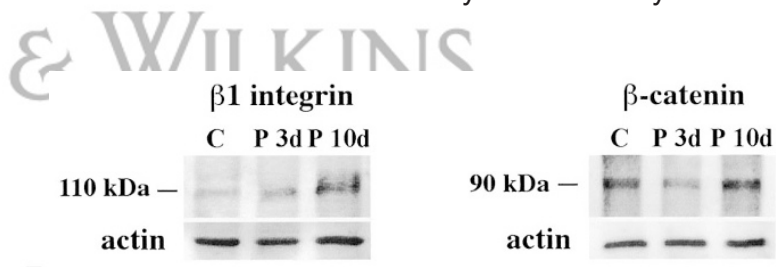

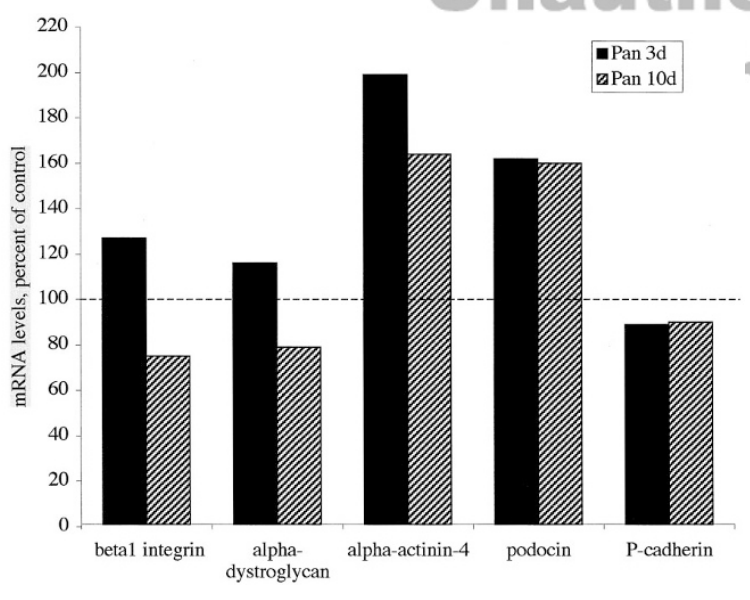

Figure 2.

Semiquantitative detection of mRNA. The effect of puromycin aminonucleoside $(\mathrm{PA})$ on the transcripts was analyzed with the NIH image analysis program. PCR runs were performed in triplicate and mean values were counted. The values were normalized with the respective $\beta$-actin mRNA levels.
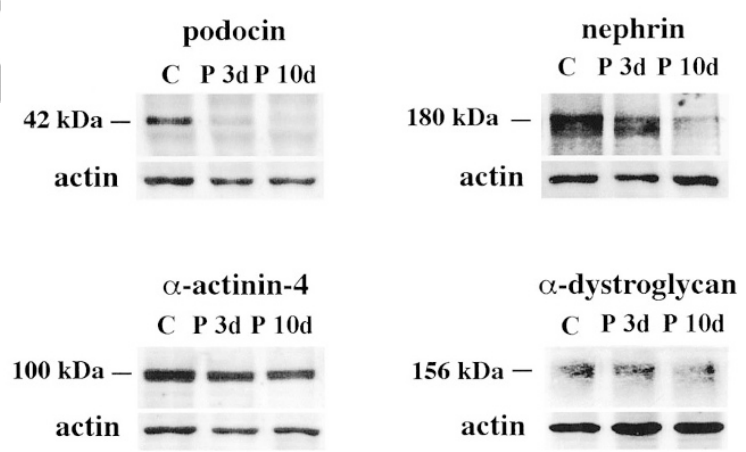

Figure 4.

Results of Western blotting analysis. The results were normalized by comparing the intensities of the wanted bands with respective actin bands. For $\beta 1$ integrin, a marked increase at 3 and 10 days is seen. The podocin blot shows an almost complete reduction in the amount of podocin in the 10-day sample, as does nephrin, the amount being roughly $25 \%$ of control. Normalization with actin is in agreement. $\beta$-catenin shows reduction at 3 days, and the control level is regained at 10 days. $\alpha$-actinin- 4 does not show relevant differences between the groups, nor does $\alpha$-dystroglycan. 
treated animals. The staining intensity for podocin decreased prominently between control and 10-day samples (Fig. 5). $\beta 1$ integrin stainings are in keeping with Western blotting quantitations, showing enhanced staining toward 10 days of induction (data not shown). The staining pattern is patchy on 10-day tissue, most probably due to the typical morphologic changes induced in the puromycin model.

\section{Discussion}

The glomerular epithelial cell, the podocyte, is a complex cell with many exclusive structural and functional properties. Because little is known about changes in the expression levels of recently discovered podocyte-associated molecules, these were included in the present study. As PA treatment leads to profound changes in the well-organized cytoskeleton of podocytes (Caulfield et al, 1976), it allows a detailed molecular analysis of diseased podocytes. Interestingly, remarkable changes were seen particularly both in nephrin and in the proteins directly associating with it, whereas negligible changes were observed in the cytoskeletal molecules of podocytes.

We have previously shown a reduction in nephrinspecific mRNA levels even before the onset of prominent proteinuria in the acute PA model in the rat (Luimula et al, 2000). The respective nephrin protein level was here measured and found similarly reduced. In humans, mutations in the NPHS1 gene encoding nephrin result in congenital nephrotic syndrome of the Finnish type (CNF). In CNF patients, as well as in the respective knock-out mice, loss of filtration slits is seen (Kestilä et al, 1998; Rantanen, Palmén, Pätäri, Ahola, Lehtonen, Åström, Floss̄, Vaūti, Wurst, Ruiz, Kerjaschki, and Holthöfer, unpublished data). Structurally, nephrin belongs to the immunoglobulin superfamily of cell adhesion molecules and, in addition to its function in the slit diaphragm structure (Holthöfer et al, 1999; Holzman et al, 1999; Kestilä, et al 1998), it is known to play an essential role in mediating cell signaling (Simons et al, 2001). However, still little is known of the emerging complex of nephrin-binding proteins as well as of their regulation at mRNA and protein levels.

The integral membrane protein podocin is mutated in recessive steroid-resistant nephrotic syndrome (Boute et al, 2000). Normally, it supposedly functions as a link between plasma membrane proteins and the cytoskeleton. A direct interaction of podocin with nephrin was recently shown (Huber et al, 2001). Our finding that nephrin and podocin proteins show a closely similar pattern of decrease during the induction of PAN agrees with that finding. The systematic finding of slightly elevated level of podocin-specific mRNA at 10 days after puromycin treatment is interesting and differs from the pattern of nephrin mRNA expression, which remains low at 10 days. This result may reflect a discordant regulation of mRNA and protein levels as seen for different cell types (Anderson and Anderson, 1998; Fincham et al, 2000; Gygi et al, 1999). Alternatively, the effects of $P A$ on various molecules may differ considerably. Still another possibility is that the half-lives of nephrin and podocin are quite different.

A group of adhesion molecules located at the basal aspect of podocytes, including dystroglycans and integrins, has an apparently important role in the dynamic attachment of podocytes (Regele et al, 2000). $\alpha 3 \beta 1$ integrin, a receptor for the extracellular matrix including components such as collagen IV and laminin, also homes in the same plasma membrane domain. These two adhesion molecules are proposedly important in stabilizing the foot processes (Regele et al, 2000).

Many/studies concerning the expression of $\alpha 3 \beta 1$ integrin of podocytes have been published (Chen et al, 2000; Regoli and Bendayan, 1997; Smoyer et al, 1997). Here, we observed up-regulation in $\beta 1$ integrin protein, whereas no appreciable shift was detected in the respective mRNA level. This increase of protein may be due to the cells' effort to stay stably attached to the GBM during the PA challenge. It has recently

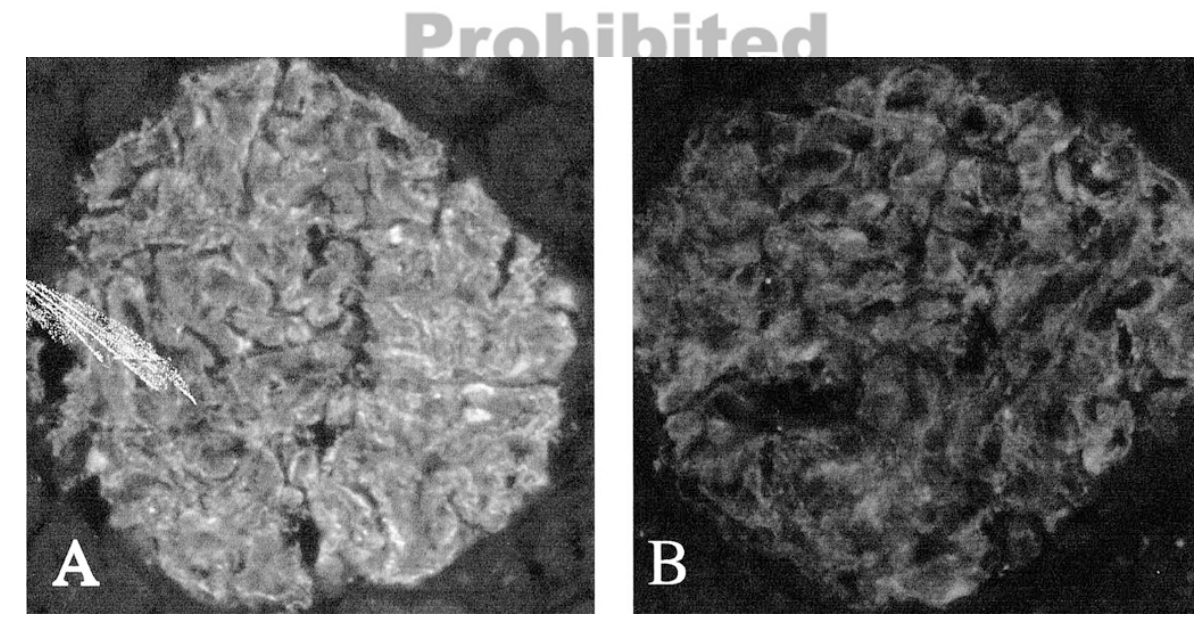

Figure 5.

Immunofluorescence staining with a polyclonal antibody to podocin. A shows an even staining of podocin in a control glomerulus. B, In a glomerulus treated for 10 days, the staining intensity is remarkably reduced, and the morphology is severely altered compared with the control in A. 
been shown that integrins and possibly integrin-linked kinase (Kretzler et al, 2001) are important for signaling in podocytes. Because integrin-mediated signaling enhances pathways through which cells react to their environment, e.g., the ERK pathway (Fincham et al, 2000), the present finding on up-regulated $\beta 1$ integrin levels may reflect the podocytes' response mechanisms in general.

Semiquantitation of $\alpha$-dystroglycan-specific mRNA showed no appreciable changes, consistent with protein quantitation. In a previous study, Regele et al (2000) have reported on reduced protein expression of dystroglycan in renal biopsies from patients with minimal change nephropathy (Regele et al, 2000). There may be a species-difference associated with the changes seen in minimal change nephropathy and the changes caused by PA. However, the methods of quantitation also differ. In the study mentioned above, quantitative immunoelectron microscopy was used, whereas our study gives the amount of specific protein in relation to a reference protein, $\beta$-actin. It is interesting to note that $\beta 1$ integrin, a preferential component of the soles of the foot processes, showed difference in its protein changes as compared with the complex of slit diaphragm-related molecules. Thus, we propose that the slit diaphragm complex of molecules is first and perhaps more severely affected in states of proteinuria, and suggests a malfunctioning cell adhesion at least in the PAN model.

$\alpha$-Actinin is a member of a family of actin-binding proteins. In addition to its intermediary role in the actin cytoskeleton, it is known to bind to the cytoplasmic domain of $\beta 1$ integrin (Otey et al, 1993) and to link the cortical cytoskeleton to the plasmalemma, to for example adherens junctions and tight junctions (Djinovic-Carugo et al, 1999). As the slit diaphragm between podocyte foot processes is suggested to present a modified adherens junction, the stable levels of $\alpha$-actinin-4 point at conserving this link despite the loss of functional filtration slits. It has been proposed that $\alpha$-actinin-4 facilitates macropinocytosis or internalization of extracellular components (Araki et al, 2000). The protein levels of $\alpha$-actinin- 4 were found unaltered at every step of PA treatment ( 3 and 10 days) compared with control. Increased mRNA levels after 3 and 10 days of induction were similar to the previous findings (Smoyer et al, 1997). However, relatively little is known of the exact functions of $\alpha$-actinin- 4 at present. The gene encoding this protein, ACTN4, is mutated in familial focal segmental glomerulosclerosis, showing its essential importance in the maintenance of podocyte integrity. As to normal function, $\alpha$-actinin- 4 crosslinks actin fibers and binds to the cytoplasmic domain of $\beta 1$ integrin in the foot processes of podocytes (Kaplan et al, 2000; Otey et al, 1993), implying that the connection from podocyte soles to the cytoskeleton is maintained even in the PAN model.

In summary, PA-treated animals showed remarkable reduction in podocin together with nephrin, and at the same time $\beta 1$ integrin was up-regulated. These results point to distinct differences in susceptibility of molecular complexes in different domains of podocytes in the PA-induced damage. Whether the same kind of changes are seen in human proteinuric diseases remains to be studied in detail.

\section{Materials and Methods}

\section{Animal Models}

Female Sprague-Dawley rats ( $n=9,150$ to $250 \mathrm{~g}$ ) were used in this study. The rats were fed standard chow and had free access to tapwater.

For the induction of PAN, a previously described protocol was used (Luimula et al, 2000). Briefly, the aminonucleoside of puromycin (10 mg/100 g ip; Sigma Chemical Company, St. Louis, Missouri) was given as a single injection intraperitoneally and the animals were killed after 3 days (group I, $n=3$ ) and 10 days (group II, $n=3$ ) of induction. Controls (group III, $n=3$ ) did not receive any treatment. Urine was collected overnight in metabolic cages at days 0,3 , and 10 . Urinary albumin was measured with nephelometry (Behringer Nephelometer 100 Analyzer; Behringerwerke, Marburg, Germany). Animals were treated according to the rules and regulations of the Ethical Committee of the University of Helsinki.

\section{Antibodies}

The primary antibodies used were: $\beta 1$ integrin- and $\beta$-catenin-specific antibodies purchased from BD Transduction Laboratories, Lexington, Kentucky; anti$\alpha$-dystroglycan purchased from Upstate Biotechnology, Lake Placid, New York; and anti-podocin polyclonal antibody kindly provided by Dr. Corinne Antignac, Paris, France. The monoclonal antibody to $\alpha$-actinin-4 was kindly provided by Dr. Tesshi Yamada, Tokyo, Japan. Anti-nephrin antibody was raised against an extracellular fragment (E2) with amino acids 780-772, as previously described (Holthöfer et al, 1999). The secondary antibodies for immunofluorescence detection, fluoresceinisothiocyanate (FITC)-conjugated affinity-purified goat antimouse IgG and FITC-conjugated swine anti-rabbit lgG, were purchased from DAKO (Glostrup, Denmark). For Western blotting, the secondary antibodies were peroxidase-conjugated, swine anti-rabbit for polyclonal and rabbit anti-mouse for monoclonal primary antibodies (DAKO).

\section{Isolation of Glomeruli and RNA}

For the isolation of glomeruli from cortical kidney tissue, samples of each group were pooled and the glomeruli were isolated as previously described (Holthöfer et al, 1991). Briefly, cortical kidney tissue was finely minced and sieved through sequential sieves of 250,150 , and $105 \mu \mathrm{m}$ pore size. The purity of the glomeruli obtained was $92 \%$ to $96 \%$ with minor tubular contamination. Total glomerular RNA was extracted by the single-step acid guanidium thiocyanate-phenol-chloroform procedure using Trizol reagent (Life Technologies, Gibco BRL, Paisley, Scot- 
land) according to the manufacturer's instructions (Chirgwin et al, 1979; Delye and Corio-Costet, 1998). For the removal of genomic DNA, the RNAs obtained were incubated with Rnase-free DNase I (Promega, Madison, Wisconsin) for 30 minutes at $37^{\circ} \mathrm{C}$ together with human placental RNase inhibitor (Promega).

\section{Semiquantitative RT-PCR}

Semiquantitative RT-PCR was used for detecting mRNA levels to determine the differences in the transcript levels of the experimental groups as described (Holthöfer et al, 1999). Briefly, $10 \mu \mathrm{g}$ of Dnase-treated RNA was reverse transcribed in the presence of an oligo $\mathrm{dT}_{15}$-primer (Boehringer Mannheim, Mannheim, Germany), RNase inhibitor and the Moloney murine leukemia virus reverse transcriptase (M-MLV RT) enzyme (Promega). cDNAs were diluted from 1:5 to $1: 3,125$ to find the range of linearity of the PCR reactions. The amounts of cDNA were equalized according to the expression levels of the housekeeping genes $\beta$-actin, GAPDH, and cyclophilin (Holthöfer et al, 1999; Kretzler et al, 1996). Sequence-specific oligonucleotide primers were designed according to rat $\alpha$-actinin-4 (5'-TATCACGCGGCGAACCA-3', 5'-TCATCCTCCTGGGCCATGT-3'), P-cadherin (5'-TCCATCATTGTGACAGACCAGAA-3', 5'-AGGCATTACTCCCTCCAGA ACA-3'), $\alpha$-dystroglycan (5'-GGACGCGAGGTGCCATT-3', 5'-CAGGAACCGTGGTACCAGCTT-3'), podocin (5'-AATTCCTTGTGCAAACCACTATGA-3', $5^{\prime}$-CCAAGGCAACCTTTGCATCT-3'), and $\beta 1$-integrin (5'-CTCTCCAGAAGGGTGGCTTTG-3', 5'-TCTCCTGTCCCATTCACTCC-3') sequences.

\section{Immunohistochemistry}

The dissected kidneys were cut into cryosections of 3 $\mu \mathrm{m}$ and fixed. For staining of $\beta 1$ integrin, the fixative was $3,5 \%$ paraformaldehyde (PFA) for 10 minutes, and for podocin, acetone for 10 minutes. The fixations were followed by repeated rinses in PBS $(140 \mathrm{~mm}$ $\mathrm{NaCl}, 2.7 \mathrm{~mm} \mathrm{KCl}, 1.5 \mathrm{~mm} \mathrm{KH}_{2} \mathrm{PO}_{4}$, 8.2 $\mathrm{mm} \mathrm{Na}_{2} \mathrm{HPO}_{4}$ $\mathrm{pH}$ 7.4) at room temperature for 15 minutes. Triton X-100 (Fluka BioChemica, Buchs, Switzerland) at $0.1 \%$ in PBS was added to the PFA fixative to enhance permeabilization. With acetone fixation, no detergent was included. To minimize unspecific binding of the antibodies, the cryosections were incubated in $10 \%$ normal rat serum (NRS) at room temperature for 30 minutes, and then by incubation with the primary antibodies diluted in 10\% NRS in PBS at room temperature for 1 hour. The mounting medium consisted of $50 \%$ glycerol in PBS (Immumount; Sigma). For fluorescence microscopy, an Olympus OX-5O microscope equipped with appropriate filter systems for FITC-fluorescence was used.

\section{Western Blotting}

The glomeruli were lysed in RIPA-buffer $(150 \mathrm{~mm} \mathrm{NaCl}$; $1 \% \mathrm{~Np}-40 ; 0.5 \%$ sodium deoxycholate; $0.1 \%$ sodium dodecyl sulfate (SDS); $50 \mathrm{~mm}$ Tris- $\mathrm{HCl}, \mathrm{pH}$ 8.0) with a glass-ware homogenizer, and the total protein con- centration was measured with BCA protein assay kit (Pierce, Rockford, Illinois). Lysates with adjusted concentrations were diluted 1:1 in Laemmli buffer containing 1:20 of $\beta$-mercaptoethanol (Fluka BioChemica) and boiled for 5 minutes. The samples were run on $8 \%$ SDS-PAGE gels with the Protean Mini-gel electrophoresis facility apparatus (Bio-Rad Laboratories, Richmond, California). The proteins were transferred onto 45-micron nitrocellulose membranes (Amersham LifeScience, Buckinghamshire, United Kingdom). The membranes were blocked with 3\% BSA in PBS overnight at $4^{\circ} \mathrm{C}$, after which they were hybridized with the respective primary antibodies at room temperature for 1 hour. This was followed by washes with $0.2 \%$ Triton $\mathrm{X}-100-\mathrm{PBS}$. The peroxidase-conjugated secondary antibodies were diluted in $0.2 \%$ Triton X-100-PBS to a dilution of 1:2,000, and hybridized on the membranes at room temperature for 1 hour. Thereafter, the filters were washed thoroughly. The peroxidase signal was enhanced using the ECL method (Amersham Pharmacia Biotech, Buckinghamshire, England) and the images were developed on Fuji Super RX films (Fuji Photo Film, Tokyo, Japan), The developed films were scanned with Biometra Gel Analyzer (BioDocAnalyze; Biometra Analytik, Göttingen, Germany) and analyzed by the NIH image analysis program (National Institutes of Health, Bethesda, Maryland).

\section{References}

Anderson NL and Anderson NG (1998). Proteome and proteomics: New technologies, new concepts, and new words. Electrophoresis 19:1853-1861.

Araki N, Hatae T, Yamada T, and Hirohashi S (2000). Actinin-4 is preferentially involved in circular ruffling and macropinocytosis in mouse macrophages: Analysis by fluorescence ratio imaging. J Cell Sci 113:3329-3340.

Boute N, Gribouval O, Roselli S, Benessy F, Lee H, Fuchshuber A, Dahan K, Gubler MC, Niaudet P, and Antignac C (2000). NPHS2, encoding the glomerular protein podocin, is mutated in autosomal recessive steroid-resistant nephrotic syndrome. Nat Genet 24:349-354.

Caulfield JP, Reid JJ, and Farquhar MG (1976). Alterations of the glomerular epithelium in acute aminonucleoside nephrosis. Evidence for formation of occluding junctions and epithelial cell detachment. Lab Invest 34:43-59.

Chen HC, Chen CA, Guh JY, Chang JM, Shin SJ, and Lai YH (2000). Altering expression of alpha3beta1 integrin on podocytes of human and rats with diabetes. Life Sci 67:23452353.

Chirgwin J, Przybyla A, MacDonald R, and Rutter W (1979). Isolation of biologically active ribonucleic acid from sources enriched in ribonuclease. Biochemistry 8:5294-5295.

Delye C and Corio-Costet MF (1998). Rapid isolation of both double-stranded RNA and PCR-suitable DNA from the obligate biotrophic phytopathogenic fungus Uncinula necator using a commercially available reagent. J Virol Methods 74:149-153.

Djinovic-Carugo K, Young $P$, Gautel $M$, and Saraste $M$ (1999). Structure of the alpha-actinin rod: Molecular basis for cross-linking of actin filaments. Cell 98:537-546. 
Fincham VJ, James M, Frame MC, and Winder SJ (2000). Active ERK/MAP kinase is targeted to newly forming cellmatrix adhesions by integrin engagement and v-Src. EMBO $\mathrm{J}$ 19:2911-2923.

Gygi SP, Rochon Y, Franza BR, and Aebersold R (1999). Correlation between protein and mRNA abundance in yeast. Mol Cell Biol 19:1720-1730.

Holthöfer H, Ahola H, Solin M-L, Wang S, Luimula P, Miettinen A, and Kerjaschki D (1999). Nephrin localizes at the podocyte filtration area and is characteristically spliced in the human kidney. Am J Pathol 155:1681-1687.

Holthöfer H, Sainio K, and Miettinen A (1991). Rat glomerular cells do not express podocytic markers when cultured in vitro. Lab Invest 65:548-557.

Holzman LB, St John PL, Kovari IA, Verma R, Holthofer H, and Abrahamson DR (1999). Nephrin localizes to the slit pore of the glomerular epithelial cell - Rapid communication. Kidney Int 56:1481-1491.

Huber TB, Kottgen M, Schilling B, Walz G, and Benzing T (2001). Interaction with podocin facilitates nephrin signaling. J Biol Chem 276:41543-41546.

Kanwar YS, Liu ZZ, Kashihara N, and Wallner El (1991). Current status of the structural and functional basis of glomerular filtration and proteinuria. Semin Nephrol 11:390 413.

Kaplan JM, Kim SH, North KN, Rennke H, Correia LA, Tong $H Q$, Mathis BJ, Rodriguez-Perez JC, Allen PG, Beggs AH, and Pollak MR (2000). Mutations in ACTN4, encoding alphaactinin-4, cause familial focal segmental glomerulosclerosis. Nat Genet 24:251-256.

Kawachi H, Koike H, Kurihara H, Yaoita E, Orikasa M, Shia MA, Sakai T, Yamamoto T, Salant DJ, and Shimizu F (2000). Cloning of rat nephrin: Expression in developing glomeruli and in proteinuric states. Kidney Int 57:1949-1961.

Kerjaschki D (1994). Dysfunctions of cell biological mechanisms of visceral epithelial cell (podocytes) in glomerular diseases. Kidney Int 45:300-313.

Kestilä M, Lenkkeri U, Männikkö M, Lamerdin J, McCready P, Putaala H, Ruotsalainen V, Morita T, Nissinen M, Herva R, Kashtan C, Peltonen L, Holmberg C, Olsen A, and Tryggvason K (1998). Positionally cloned gene for a novel glomerular protein-nephrin is mutated congenital nephrotic syndrome. Mol Cell 1:575-582.

Kreidberg JA (2000). Functions of alpha3beta1 integrin. Curr Opin Cell Biol 12:548-553.
Kretzler M, Fan G, Rose D, Arend LJ, Briggs JP, and Holzman LB (1996). Novel mouse embryonic renal marker gene products differentially expressed during kidney development. Am J Physiol 271:F770-777.

Kretzler M, Teixeira VP, Unschuld PG, Cohen CD, Wanke R, Edenhofer I, Mundel P, Schlondorff D, and Holthofer $\mathrm{H}$ (2001). Integrin-linked kinase as a candidate downstream effector in proteinuria. FASEB J 15:1843-1845.

Kubosawa $\mathrm{H}$ and Kondo $\mathrm{Y}$ (1994). Modulation of cytoskeletal organization of podocytes during the course of aminonucleoside nephrosis in rats. Pathol Int 44:578-586.

Luimula P, Ahola H, Wang SX, Solin ML, Aaltonen P, Tikkanen I, Kerjaschki D, and Holthofer H (2000). Nephrin in experimental glomerular disease. Kidney Int 58:1461-1468.

Otey CA, Vasquez GB, Burridge K, and Erickson BW (1993). Mapping of the alpha-actinin binding site within the beta 1 integrin cytoplasmic domain. J Biol Chem 268:21193-21197.

Regele HM, Fillipovic E, Langer B, Poczewki H, Kraxberger I, Bittner RE, and Kerjaschki D (2000). Glomerular expression of dystroglycans is reduced in minimal change nephrosis but not in focal segmental glomerulosclerosis. J Am Soc Nephrol 11:403-412.

Regoli M and Bendayan M (1997). Alterations in the expression of the alpha 3 beta 1 integrin in certain membrane domains of the glomerular epithelial cells (podocytes) in diabetes mellitus. Diabetologia 40:15-22.

Reiser J, Kriz W, Kretzler M, and Mundel P (2000). The glomerular slit diaphragm is a modified adherens junction. J Am Soc Nephrol 11:1-8.

Simons M, Schwarz K, Kriz W, Miettinen A, Reiser J, Mundel $P$, and Holthofer $H$ (2001). Involvement of lipid rafts in nephrin phosphorylation and organization of the glomerular slit diaphragm. Am J Pathol 159:1069-1077.

Smoyer WE, Mundel P, Gupta A, and Welsh MJ (1997). Podocyte alpha-actinin induction precedes foot process effacement in experimental nephrotic syndrome. Am J Physiol 273:F150-157.

Whiteside Cl, Cameron R, Munk S, and Levy J (1993). Podocytic cytoskeletal disaggregation and basementmembrane detachment in puromycin aminonucleoside nephrosis. Am J Pathol 142:1641-1653. 